\title{
Níveis de lisina digestível em rações, utilizando-se o conceito de proteína ideal, para suínos machos castrados de alto potencial genético dos 15 aos $30 \mathbf{k g}^{1}$
}

\author{
Márvio Lobão Teixeira de Abreu², Juarez Lopes Donzele ${ }^{3}$, Rita Flávia Miranda de Oliveira ${ }^{3}$, \\ Alexandre Luis Siqueira de Oliveira ${ }^{4}$, Francisco Carlos de Oliveira Silva ${ }^{5}$, Antônio Marcos Souto Moita ${ }^{6}$ \\ ${ }^{1}$ Parte da tese de Doutorado do primeiro autor \\ ${ }^{2}$ DZO/UFPI \\ ${ }^{3}$ DZO/UFV \\ ${ }^{4}$ Fiscal de Defesa Agropecuária. \\ ${ }^{5}$ EPAMIG. \\ ${ }^{6}$ AGROCERES
}

RESUMO - Foram utilizados 40 leitões machos castrados, de alto potencial genético para deposição de carne magra na carcaça, com pesos inicial e final de $15,76 \pm 0,93$ e $30,23 \pm 1,56 \mathrm{~kg}$, respectivamente, para avaliar o efeito de níveis de lisina digestível, utilizando-se o conceito de proteína ideal, sobre o desempenho e a composição da carcaça. Os tratamentos corresponderam a uma ração basal com 19,46\% de PB e $3.280 \mathrm{kcal}$ de $\mathrm{EM} / \mathrm{kg}$, suplementada com L-lisina $\mathrm{HCl}$, resultando em rações com 0,$90 ; 1, .00 ; 1,10$ e $1,20 \%$ de lisina digestível. As rações foram suplementadas com níveis crescentes de aminoácidos sintéticos, resultando em rações com relações constantes entre metionina + cistina, treonina, triptofano e valina com a lisina (60, 60, 19 e 69\%, respectivamente), com base na digestibilidade verdadeira. Não se observou efeito dos tratamentos sobre o consumo diário de ração, a concentração de uréia no plasma e as porcentagens de água, proteína e gordura na carcaça dos animais. Houve efeito quadrático dos níveis de lisina digestível sobre o ganho de peso diário, que aumentou até o nível estimado de 1,10\% de lisina na ração, e a conversão alimentar, que melhorou até o nível estimado de $1,12 \%$. Houve efeito dos tratamentos sobre o consumo diário de lisina, que aumentou de forma linear. As deposições de proteína e gordura na carcaça foram influenciadas de forma quadrática, aumentando até os níveis estimados de 1,12 e 1,08\% de lisina digestível, respectivamente. O nível de 1,12\% de lisina digestível foi o que proporcionou os melhores resultados de desempenho e de características de carcaça de suínos machos castrados de alto potencial genético na fase de 15 a $30 \mathrm{~kg}$, o que correspondeu a um consumo de lisina digestível de 12,03 g/dia (3,42 g de Lis/Mcal de EM).

Palavras-chave: aminoácidos, carcaça, fase inicial, genótipo, leitões, uréia

\section{Dietary digestible lysine levels, using the ideal protein concept, for barrows with high genetic potential from 15 to $30 \mathrm{~kg}$}

ABSTRACT - Fourty barrows with high genetic potential for lean gain averaging initial and final body weights of $15.76 \pm 0.93 \mathrm{~kg}$ and $30.23 \pm 1.56 \mathrm{~kg}$, respectively, were used to evaluate the effect of digestible lysine levels, using the ideal protein concept, on the performance and carcass composition. The treatments were composed of a basal diet containing $19.46 \%$ crude protein and 3,280 kcal of ME $/ \mathrm{kg}$, that were supplemented with different levels of HCl-L-Lysine, resulting in diets with $0.90,1.00,1,10$, and $1.20 \%$ of digestible lysine. The diets were supplemented with increasing levels of synthetic amino acids, resulting in diets with ratios of methionine + cystine, threonine, tryptophan and valine:lysine constant in 60 , 60, 19 e 69\%, respectively, based on the true digestibility. No treatment effects on feed intake, concentration of plasma urea and percentages of water, protein and fat in the carcass were observed in this trial. However, significant quadratic effects on weight gain and feed:gain ratio with quadractic maximum and minimum of 1.10 and $1.12 \%$ of lysine, respectively, were detected. Intake of digestible lysine increased linearly among treatments. The depositions of protein and fat in the carcass answered quadractily with quadratic maxima at 1.12 and $1.08 \%$, respectively. The level of digestible lysine that provided the best results of performance and carcass characteristics of barrows with high genetic potential from 15 to $30 \mathrm{~kg}$ was of $1.12 \%$ of true digestible lysine, corresponding to a digestible lysine intake of $12.03 \mathrm{~g} /$ day ( $3.42 \mathrm{~g}$ of Lys/Mcal of ME).

Key Words: amino acids, carcass, genotype, nursery phase, piglets, urea

\section{Introdução}

O crescimento dos suínos é resultado de uma série de processos biológicos, de modo que o genótipo determi- na o nível máximo em que estes processos ocorrem. $\mathrm{O}$ processo metabólico mais importante é a retenção de nitrogênio, representada pela deposição de proteína na carcaça. 
A deposição de proteína corporal, quando associada ao conteúdo de água, é caracterizada de diferentes formas: crescimento muscular, crescimento de tecido magro, crescimento de carne magra e rendimento de carne magra.

O crescimento de tecido magro segue o modelo curvilinear do ganho de peso dos suínos (Ellis, 1998). Em termos absolutos, o crescimento de tecido magro é pequeno no início, aumenta rapidamente e alcança o máximo entre os 40 e $75 \mathrm{~kg}$ de peso corporal, para então diminuir com diferentes intensidades (Schinckel \& De Lange, 1996).

Os atuais genótipos de suínos introduzidos no mercado têm como principal característica econômica a maior deposição de carne magra na carcaça. Como o aumento do tecido magro é o principal objetivo da criação de suínos para o abate, ele representa o fator que mais influencia as exigências de aminoácidos, principalmente de lisina. Essas exigências são influenciadas por fatores como genética, peso corporal, sexo e ambiente (temperatura, status sanitário etc), que, portanto, devem ser considerados no estabelecimento das necessidades de proteína e aminoácidos.

A lisina dietética é o nutriente que mais influencia a deposição de proteína pelos suínos em crescimento, em virtude de sua constância na proteína corporal e de sua destinação metabólica preferencial para a deposição de tecido magro (Kessler, 1998). Assim, a exigência de lisina para suínos pode ser obtida a partir da taxa de deposição de proteína na carcaça dos animais.

Em rações para suínos, quando o nível de suplementação de um aminoácido essencial é inadequado e o de lisina suficiente, as respostas dos animais podem ser limitadas pelo aminoácido deficiente. Em experimentos para determinação da exigência de lisina, é fundamental considerar o balanço ideal dos aminoácidos nas rações experimentais (proteína ideal) para evitar variação nas respostas dos animais.

No Brasil, existe carência de informações sobre o nível de lisina digestível que possibilita a maior deposição de proteína na carcaça de suínos com elevado potencial genético para produção de carne magra na fase inicial de crescimento. Assim, esse trabalho foi conduzido para se determinar a exigência de lisina digestível em suínos machos castrados de 15 a $30 \mathrm{~kg}$, com alto potencial genético para deposição de carne magra na carcaça, utilizando-se o conceito de proteína ideal.

\section{Material e Métodos}

O experimento foi conduzido no Setor de Suinocultura do Departamento de Zootecnia da Universidade Federal de Viçosa, no período de maio a junho de 2002.

Foram utilizados 40 suínos machos castrados com alto potencial genético para deposição de carne magra na carcaça, com peso inicial de 15,76 \pm 0,93 kg, distribuídos em delineamento experimental de blocos ao acaso, com quatro tratamentos (níveis de lisina digestível), cinco repetições e dois animais por unidade experimental. Na distribuição dos animais dentro de cada bloco, foi adotado, como critério, o peso dos animais.

Os animais foram alojados em gaiolas metálicas suspensas com piso e laterais telados, dotadas de comedouros semi-automáticos e bebedouros tipo chupeta, localizadas em galpão de alvenaria, com piso de concreto e teto de madeira rebaixado.

As rações experimentais (Tabela 1), à base de milho e farelo de soja, foram suplementadas com minerais e vitaminas para atender às exigências dos animais, de acordo com Rostagno et al. (2000), exceto as exigências de PB e lisina. Os tratamentos, que consistiram de diferentes níveis de lisina digestível, foram obtidos a partir da inclusão de três níveis de L-lisina $\mathrm{HCl}$ em substituição ao amido, resultando em rações com 0,$90 ; 1,00 ; 1,10$ e 1,20\% de lisina digestível.

Em cada nível de lisina avaliado, procurou-se manter a relação metionina + cistina, triptofano e valina com lisina, com base na proteína ideal preconizada por Rostagno et al. (2000), e a relação treonina:lisina, com base na proteína ideal recomendada pelo NRC (1998) para suínos na fase inicial de crescimento. As rações e a água foram fornecidas à vontade.

As rações, as sobras e os desperdícios foram pesados semanalmente e os animais, no início e no final do período experimental, quando atingiram $30,23 \pm 1,56 \mathrm{~kg}$, para determinação do consumo de ração e de lisina, do ganho de peso e da conversão alimentar.

Ao final do experimento, um animal de cada unidade experimental com peso mais próximo da média da gaiola foi utilizado para avaliar a composição química e as deposições de proteína e gordura na carcaça. Após jejum de 24 horas, os animais foram abatidos por sangramento, depilados com lança-chamas e faca e eviscerados. As carcaças inteiras, incluindo cabeça e pés, foram pesadas.

Posteriormente, a meia-carcaça direita foi triturada por 20 minutos, em cutter comercial de $30 \mathrm{HP}$ e 1.775 rpm. Após homogeneização, amostras foram retiradas para análises, conforme metodologia descrita por Donzele et al. (1992), e armazenadas $\mathrm{a}-12^{\circ} \mathrm{C}$.

O outro animal da unidade experimental, após jejum alimentar de 24 horas, recebeu ração à vontade por 1 hora. Após esse período, estes animais retornaram ao jejum alimentar e hídrico por mais 5 horas, quando, então, foi feita a coleta de sangue por meio de punção do sinus orbital. O sangue foi centrifugado a $3.000 \mathrm{rpm}$, durante 15 minutos, para obtenção do plasma, que, em seguida, foi armazenado em congelador para posterior determinação da concentração 
Tabela 1 - Composições centesimal e nutricional das rações experimentais

Table 1 - Imgredient and nutritional compositions of the experimental diets

Ingrediente

Ingredient
Nível de lisina digestível (\%)

Digestible lysine level

\begin{tabular}{|c|c|c|c|c|}
\hline & 0,90 & 1,00 & 1,10 & 1,20 \\
\hline Milho (Corn) & 57,050 & 57,050 & 57,050 & 57,050 \\
\hline Farelo de soja (Soybean meal) & 31,970 & 31,970 & 31,970 & 31,970 \\
\hline Açúcar (Sugar) & 3,000 & 3,000 & 3,000 & 3,000 \\
\hline Amido (Corn starch) & 1,000 & 0,796 & 0,547 & 0,227 \\
\hline Óleo de soja (Soybean oil) & 2,750 & 2,750 & 2,750 & 2,750 \\
\hline Fosfato bicálcico (Dicalcium phosphate) & 1,750 & 1,750 & 1,750 & 1,750 \\
\hline Calcário (Limestone) & 0,720 & 0,720 & 0,720 & 0,720 \\
\hline L-lisina $\mathrm{H}-\mathrm{Cl}$ ( $\mathrm{HCl}$ L-lysine) & - & 0,127 & 0,254 & 0,381 \\
\hline Dl-metionina (DL-methionine) & - & 0,046 & 0,107 & 0,168 \\
\hline L-treonina (L-threonine) & - & 0,031 & 0,092 & 0,153 \\
\hline L-triptofano (L-thryptophan) & - & - & - & 0,020 \\
\hline L-valina (L-valine) & - & - & - & 0,051 \\
\hline Sal comum (Salt) & 0,350 & 0,350 & 0,350 & 0,350 \\
\hline Premix mineral (Mineral mix) ${ }^{1}$ & 0,100 & 0,100 & 0,100 & 0,100 \\
\hline Premix vitamínico $(\text { Vitamin mix })^{2}$ & 0,300 & 0,300 & 0,300 & 0,300 \\
\hline Promotor crescimento (Growth promoter) ${ }^{3}$ & 1,000 & 1,000 & 1,000 & 1,000 \\
\hline BHT & 0,010 & 0,010 & 0,010 & 0,010 \\
\hline
\end{tabular}

Composição nutricional calculada ${ }^{4}$

Calculated nutritional composition

Energia digestível (kcal/kg) (Digestible energy)

Energia metabolizável ( $\mathrm{kcal} / \mathrm{kg}$ ) (Metabolizable energy)

Proteína bruta (\%) (Crude protein)

Lisina total (\%) (Total lysine)

Lisina digestível $(\%)^{5}$ (Digestible lysine)

Metionina + cistina digestível $(\%)^{5}$ (Digetsible methionine + cystine)

Treonina digestível $(\%)^{5}$ (Digestible threonine)

Triptofano digestível $(\%)^{5}$ (Digestible thryptophan)

Valina digestível $(\%)^{5}$ (Digestible valine)

Cálcio (\%) (Calcium)

Fósforo disponível (\%) (Available phosphorus)

Sódio (\%) (Sodium)

$\begin{array}{cc}3.465 & 3.465 \\ 3.280 & 3.280 \\ 19,460 & 19,630 \\ 1,031 & 1,133 \\ 0,900 & 1,000 \\ 0,554 & 0,600 \\ 0,570 & 0,600 \\ 0,213 & 0,213 \\ 0,784 & 0,784 \\ 0,830 & 0,830 \\ 0,430 & 0,430 \\ 0,180 & 0,180\end{array}$

3.465

3.280

19,840

1,234

1,100

0,660

0,660

0,213

0,784

0,830

0,430

0,180
3.465

3.280

20,060

1,335

1,200

0,720

0,720

0,230

0,834

0,830

0,430

0,180

1 Conteúdo/kg de produto (Content/kg of product): Ca (98,80 g); Co (185 mg); Cu (15.750 mg); Fe (26.250 mg); I (1.470 mg); Mn (41.850 mg); Zn (77.999 mg).

2 Conteúdo/kg de produto (Content/kg of product): Ácido fólico (Folic acid) - $420 \mathrm{mg}$; Ácido pantotênico (Pantothenic acid) - 7.350 mg; Antioxidante (Antioxidant) (BHT) - $1.500 \mathrm{mg}$; Biotina (Biotin) - 16,56 mg; Colina (Choline) - $126 \mathrm{~g}$; Niacina - (Niacin) $13.650 \mathrm{mg}$; Piridoxina (Pyridoxine) - $700 \mathrm{mg}$; Riboflavina (Riboflavine) - $2.100 \mathrm{mg}$; Selênio (Selenium) 136,50 mg; Tiamina (Thiamin) - $700 \mathrm{mg}$; Vit. A (2.800 UI); Vit. B12 (11.550 mcg); Vit. D3 (1.050 UI); Vit. E $(10.500 \mathrm{mg})$ e Vit. K3 $(2.800 \mathrm{mg})$

3 Olaquindox: $11.000 \mathrm{mg} / \mathrm{kg}$.

4 Composição calculada segundo Rostagno et al. (2000) (Calculated composition according to Rostagno et al., 2000 tables).

${ }^{5}$ Valores estimados com base nos coeficientes de digestibilidade dos aminoácidos dos ingredientes, de acordo com Rostagno et al. (2000) (Estimated values based on the coefficients of digestibility of ingredient amino acids according to Rostagno et al., 2000 tables).

de uréia plasmática (UPL) por meio de processo enzimático, utilizando-se kit comercial.

Um grupo adicional de quatro animais da mesma linhagem, com $15,00 \pm 0,27 \mathrm{~kg}$, foi abatido para determinação da composição da carcaça dos suínos no início do experimento.

Em razão do alto teor de gordura, as amostras das carcaças dos animais foram submetidas à pré-secagem em estufa de ventilação forçada $\left(60^{\circ} \mathrm{C}\right.$, por 72 horas $)$, seguida de pré-desengorduramento pelo método a quente, por quatro horas, em extrator tipo Soxhlet. As amostras pré-secas e pré-desengorduradas foram processadas em moinho de bola, acondicionadas em vidros e conservadas em geladeira para análises posteriores. A água e a gordura retiradas durante o preparo inicial das amostras foram consideradas nos cálculos dos teores de água, proteína e gordura da carcaça.

As análises dos ingredientes das rações e das quantidades de água, proteína e gordura das carcaças dos animais foram realizadas no Laboratório de Nutrição Animal do Departamento de Zootecnia da UFV, de acordo com técnicas descritas por Silva (1990).

As deposições de proteína e gordura nas carcaças foram calculadas comparando-se as composições das carcaças dos animais no início e no fim do período experimental.

As análises estatísticas das variáveis de desempenho, das concentrações de uréia no plasma dos animais, da composição da carcaça e das deposições de proteína e gordura nas carcaças foram realizadas utilizando-se o 
Sistema de Análises Estatísticas e Genética-SAEG, desenvolvido na UFV (1997).

As estimativas de exigência de lisina digestível foram determinadas por meio de análises de regressão linear e quadrática.

\section{Resultados e Discussão}

Os resultados de desempenho, consumo diário de lisina digestível e concentração de uréia no plasma de suínos machos castrados de 15 a $30 \mathrm{~kg}$, em função do nível de lisina na ração, encontram-se na Tabela 2.

O consumo de ração diário (CRD) não foi influenciado $(\mathrm{P}>0,05)$ pelos níveis de lisina da ração, de forma semelhante ao observado por Souza (1997), Moretto et al. (2000), Kendalll et al. (2003) e Urynek \& Buracnewska (2003).

Avaliando o aumento da relação lisina:caloria, Smith et al. (1999), utilizando leitões de 10 a 25 kg, e Roth et al. (1999), em leitões de 8 a $30 \mathrm{~kg}$, também não verificaram efeito dos tratamentos sobre o CRD dos animais.

Segundo Edmonds \& Baker (1987), suínos podem tolerar consideráveis excessos de aminoácidos, especialmente lisina, sem apresentar variações significativas no consumo alimentar.

Outra justificativa para a ausência de variação do CRD seria a manutenção das relações dos principais aminoácidos digestíveis com a lisina por meio da suplementação das rações com aminoácidos sintéticos, evitando o possível desbalanço de aminoácidos, que, segundo D’Mello (1993), resulta em redução no consumo de alimento. Henry (1985), em artigo de revisão, concluiu que o consumo de alimento pode ser negativamente influenciado por deficiência de aminoácido limitante ou por excessivo suprimento de proteína ou aminoácidos.

James et al. (2002) e Fontes et al. (2005), no entanto, verificaram que o CRD variou de formas linear e quadrática, respectivamente, conforme o nível de lisina na ração. Esses autores constataram, todavia, que o aumento dos níveis de lisina não foi acompanhado por aumentos nas concentrações dos demais aminoácidos essenciais, o que pode ter provocado o desbalanço de aminoácidos, explicando, em parte, as diferenças em relação a este estudo. Quanto ao consumo de lisina digestível diário (CLD), observou-se aumento linear $(\mathrm{P}<0,01)$ conforme o aumento do nível de lisina das rações (Figura 1). Resultados semelhantes ao deste estudo foram encontrados por Souza (1997), Moretto et al. (2000), Colina et al. (2003) e Fontes et al. (2005). Como o consumo de ração pelos animais não variou significativamente entre os tratamentos, o aumento do consumo de lisina digestível ocorreu em razão direta dos aumentos de suas concentrações nas rações.

Os tratamentos influenciaram $(\mathrm{P}<0,01)$ de forma quadrática o ganho de peso diário (GPD), que aumentou até o nível estimado de 1,10\% de lisina digestível, correspondente a um consumo de lisina digestível de 11,81 g/dia (Figura 2). Resultado semelhante ao deste estudo foi encontrado por James et al. (2002), ao trabalharem com leitões de 12 a $20 \mathrm{~kg}$, e por Fontes et al. (2005), com leitões dos 15 aos $30 \mathrm{~kg}$.

Outros autores, como Moretto et al. (2000), em experimentos com suínos machos inteiros e fêmeas dos 15 aos $35 \mathrm{~kg}$, e Merino et al. (2003), com suínos machos castrados na fase inicial, também verificaram efeito positivo dos níveis de lisina da ração sobre o GPD dos animais. Em contrapartida, Souza (1997) e Urynek \& Buracnewska (2003), avaliando níveis de lisina para suínos machos castrados na fase inicial, não observaram efeito dos tratamentos sobre o GPD dos animais.

A diferença de respostas no GPD de suínos constatada entre os trabalhos pode estar relacionada, entre outros fatores, a diferenças no padrão genético dos animais quanto ao potencial de crescimento muscular (Stahly et al., 1994).

O comportamento obtido para o GPD dos animais neste estudo, em função do nível de lisina da ração, revela que

Tabela 2 - Desempenho, consumo diário de lisina digestível e nível de uréia no plasma de suínos machos castrados de 15 a 30 kg, de acordo com o nível de lisina da ração

Table 2 - Performance, digestible lysine intake and plasma urea level of barrows from 15 to $30 \mathrm{~kg}$ according to the dietary lysine level

\begin{tabular}{|c|c|c|c|c|c|}
\hline \multirow[t]{2}{*}{$\begin{array}{l}\text { Parâmetro } \\
\text { Parameter }\end{array}$} & \multicolumn{4}{|c|}{$\begin{array}{c}\text { Nível de lisina digestível (\%) } \\
\text { Digestible lysine level }\end{array}$} & \multirow[t]{2}{*}{$\mathrm{CV}(\%)$} \\
\hline & 0,90 & 1,00 & 1,10 & 1,20 & \\
\hline Consumo de lisina digestível $(\mathrm{g} / \mathrm{dia})^{1}$ (Digestible lysine intake) $^{-}$ & 9,38 & 10,92 & 12,07 & 12,68 & 11,42 \\
\hline Ganho de peso diário $(\mathrm{g})^{2}$ (Daily weight gain) & 607 & 732 & 778 & 731 & 7,03 \\
\hline Conversão alimentar $(\mathrm{g} / \mathrm{g})^{3}$ (Feed:gain ratio) & 1,72 & 1,49 & 1,41 & 1,45 & 8,16 \\
\hline
\end{tabular}

1 Efeito linear $(P<0,01)$.

2,3 Efeito quadrático, $P<0,01$ e $P<0,05$, respectivamente.

1 Linear effect $(P<0.01)$.

2,3 Quadractic effect, $P<0.01$ and $P<0.05$, respectively. 


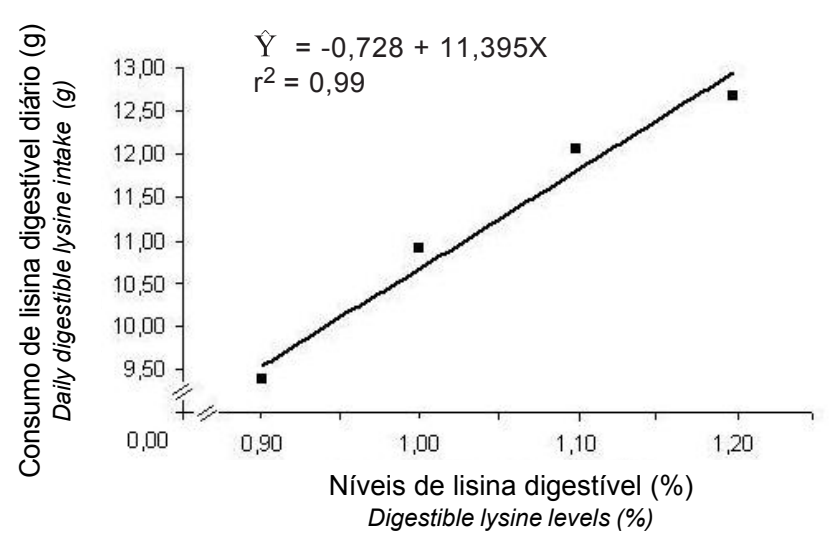

Figura 1 - Efeito dos níveis de lisina digestível da ração sobre o consumo diário de lisina digestível de suínos machos castrados de 15 a $30 \mathrm{~kg}$.

Figure 1 - Effect of dietary digestible lysine levels on daily digestible lysine intake of barrows from 15 to $30 \mathrm{~kg}$.

suínos com alto potencial genético para deposição de carne magra na carcaça respondem a níveis crescentes de lisina até o ponto determinado pelo potencial genético.

O nível de lisina digestível que proporcionou os melhores resultados de GPD dos animais $(1,10 \%)$ foi superior aos de 1,08 e $0,84 \%$ obtidos por Souza (1997) e Moretto et al. (2000), respectivamente, para animais de 15 a $30 \mathrm{~kg}$. As variações na capacidade genética de deposição de proteína podem explicar as diferenças entre os estudos. Segundo Friesen et al. (1994), além da mais elevada capacidade de deposição de proteína, suínos melhorados possuem menor consumo de ração, o que pode justificar as mais altas exigências de lisina em porcentagem da ração. Entretanto, Fontes et al. (2005), trabalhando com leitoas de alto potencial genético na mesma faixa de peso, encontraram, para melhores resultados de GPD, nível de 1,22\% de lisina digestível, correspondente a consumo diário de lisina de $14,75 \mathrm{~g}$, superior ao encontrado neste estudo $(12,03 \mathrm{~g})$.

A conversão alimentar (CA) foi influenciada $(\mathrm{P}<0,05)$ de forma quadrática pelos tratamentos, melhorando até o nível estimado de 1,12\% de lisina digestível, correspondente ao consumo de lisina digestível de 12,03 g/dia (Figura 3). Este resultado é semelhante ao nível de 1,13\% de lisina digestível obtido por Fontes et al. (2005) para leitoas de 15 a $30 \mathrm{~kg}$. Por outro lado, níveis inferiores aos deste experimento foram obtidos por Moretto et al. (2000), que, em experimento com leitoas puras da raça Landrace, estimaram em $1,08 \%$ o nível de lisina total, que proporcionou os melhores resultados de conversão alimentar.

Não houve efeito $(\mathrm{P}>0,05)$ dos níveis de lisina da ração sobre a concentração de uréia no plasma (UPL) dos animais. Resultado semelhante foi encontrado por Fontes et al. (2005).

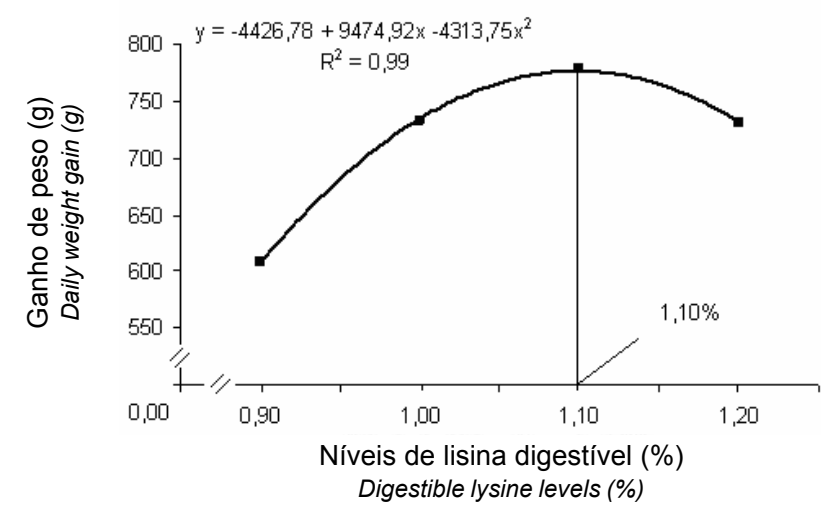

Figura 2 - Efeito dos níveis de lisina digestível da ração sobre o ganho de peso diário de suínos machos castrados de 15 a $30 \mathrm{~kg}$.

Figure 2 - Effect of dietary digestible lysine levels on daily weight gain of barrows from 15 to $30 \mathrm{~kg}$.

Os níveis de lisina consumidos acima das necessidades de mantença e de deposição de proteína são catabolisados, de modo que o nitrogênio resultante desse catabolismo é excretado como uréia. Dessa forma, segundo Cameron et al. (2003), a relação entre a uréia plasmática e a lisina na ração deve ser não-linear, ocorrendo um ponto de inflexão no nível de lisina correspondente à exigência do animal.

Neste estudo não houve ponto de inflexão para UPL em resposta aos níveis de lisina na ração, indicando que este parâmetro não foi efetivo na determinação da exigência de lisina para suínos de 15 a $30 \mathrm{~kg}$. Conforme relatado por Cameron et al. (2003), o uso da uréia sangüínea como parâmetro para predição da exigência de lisina deve ser limitado para animais com peso acima de $70 \mathrm{~kg}$. Do mesmo modo, Friesen et al. (1994) concluíram que o teor de uréia no sangue não é um parâmetro adequado para estimativa das exigências de lisina de animais em crescimento.

Segundo Fontes et al. (2005), o padrão desuniforme de consumo de ração dos animais após o período de jejum, durante o protocolo de coleta de sangue, pode ser uma das causas da variabilidade nos valores de uréia sangüínea, resultando no alto coeficiente de variação verificado para este parâmetro. É possível que o número de repetições utilizado neste trabalho tenha sido insuficiente para utilizar a uréia plasmática como preditor da exigência de lisina para suínos de 15 a $30 \mathrm{~kg}$.

Os resultados da composição química e das deposições de proteína e gordura na carcaça de suínos machos castrados de 15 a $30 \mathrm{~kg}$, de acordo com o nível de lisina da ração, são apresentados na Tabela 3 .

Não houve efeito $(\mathrm{P}>0,05)$ dos níveis de lisina sobre as porcentagens de água, proteína e gordura da carcaça dos animais. Os resultados de porcentagem de água e proteína na 


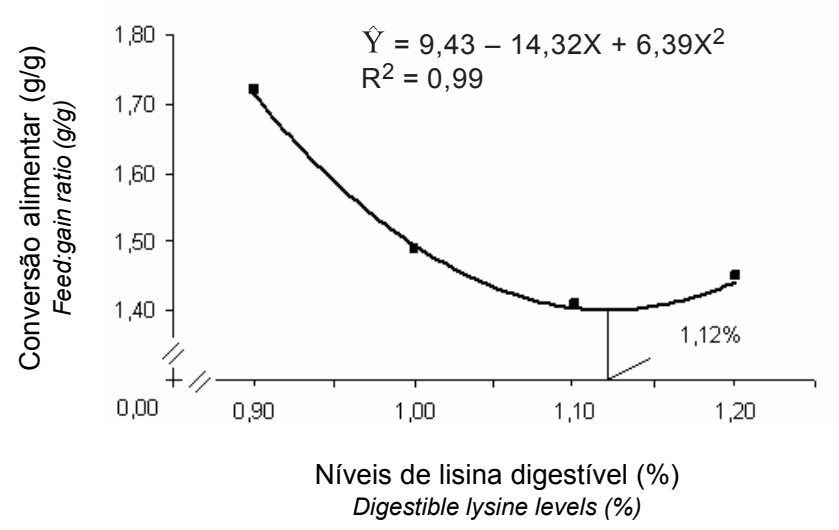

Figura 3 - Efeito dos níveis de lisina digestível da ração sobre a conversão alimentar de suínos machos castrados de 15 a $30 \mathrm{~kg}$.

Figure 3 - Effect of dietary digestible lysine levels on feed:gain ratio of barrows from 15 to $30 \mathrm{~kg}$.

carcaça são semelhantes aos obtidos por Fontes et al. (2005), em animais de 15 a $30 \mathrm{~kg}$, enquanto os de porcentagem de água e gordura foram similares aos encontrados por Trindade Neto et al. (2004), em animais de 12 a $19 \mathrm{~kg}$. Por outro lado, efeitos dos níveis de lisina da ração sobre a porcentagem de gordura e proteína na carcaça foram observados por Fontes et al. (2005) e Trindade Neto et al. (2004), respectivamente.

A deposição de proteína na carcaça (DP) dos animais variou $(\mathrm{P}<0,05)$ de forma quadrática em função dos tratamentos, aumentando até o nível estimado de $1,12 \%$ de lisina digestível, correspondente ao consumo de lisina digestível de 12,03 g/dia (Figura 4).

$\mathrm{O}$ aumento na DP neste estudo indica que quando a energia da ração não é fator limitante, os suínos respondem aos níveis de lisina da ração até o ponto de máxima deposição de proteína no corpo determinado pela genética.
Os valores de DP (97,2 g/dia) foram superiores aos verificados por Trindade Neto et al. (2004) e inferiores aos obtidos por Fontes et al. (2005), de 70,0 e 125,6 g/dia, respectivamente.

$\mathrm{O}$ valor de lisina digestível estimado para máxima DP neste estudo foi próximo ao nível estimado para os melhores resultados de ganho de peso $(1,10 \%)$ e coincidiu com aquele que promoveu os melhores resultados para conversão alimentar dos animais $(1,12 \%)$. O ponto de máxima deposição de proteína na carcaça é, segundo De Lange et al. (2001), o ponto no qual o animal atinge a máxima eficiência alimentar.

Associando os resultados de deposição de proteína na carcaça com os de GPD, pode-se inferir que o aumento quadrático do GPD resultou do aumento quadrático da DP.

A deposição de gordura (DG) na carcaça dos animais foi influenciada $(\mathrm{P}<0,05)$ de forma quadrática pelos níveis de lisina digestível da ração, segundo a equação $\hat{Y}=-775,42$ $+1600,68 \mathrm{X}-741,67 \mathrm{X}^{2}\left(\mathrm{r}^{2}=0,89\right)$, aumentando até o nível estimado de $1,08 \%$ de lisina digestível. Como a porcentagem de gordura da carcaça dos animais não foi diferente entre os tratamentos, a DG na carcaça dos animais variou conforme o ganho de peso dos animais.

A tendência verificada para a DG não era esperada quando da associação desta variável aos resultados de DP e CA. Considerando-se que a máxima eficiência alimentaré atingida no ponto em que o animal atinge seu potencial para deposição de proteína, seria esperado que menor quantidade de energia da ração estivesse disponível para deposição de gordura na carcaça, como relatado por Fontes et al. (2005) em pesquisa realizada com animais na mesma fase de crescimento.

Em contrapartida, alguns pesquisadores (Chung \& Baker, 1992; Maxwell, 1996) demonstraram que a substituição parcial da PB da ração por aminoácidos sintéticos, segundo o padrão de proteína ideal, pode resultar em aumento do

Tabela 3 - Composição química e deposições de proteína e gordura na carcaça de suínos machos castrados de 15 a 30 kg, de acordo com o nível de lisina da ração

Table 3 - Chemical composition and protein and fat depositions in the carcass of barrows from 15 to $30 \mathrm{~kg}$ according to the dietary lysine level

Parâmetro

Parameter

Nível de lisina digestível (\%)

Digestible lysine level

$1,00 \quad 1,10$

Composição da carcaça (\%) Carcass composition

Água (Water)

Proteína (Protein)

Gordura (Fat)

$$
0,90
$$

64,13
16,72
13,07

64,53

16,41

13,41

62,41
17,87
13,66

13,66

Deposição na carcaça (g/dia) Carcass deposition (g/day)

Proteína (Protein $)^{1}$

Gordura (Fat $)^{1}$

${ }^{1}$ Efeito quadrático $(P<0,05)$.

1 Effect quadractic $(P<0.05)$. 


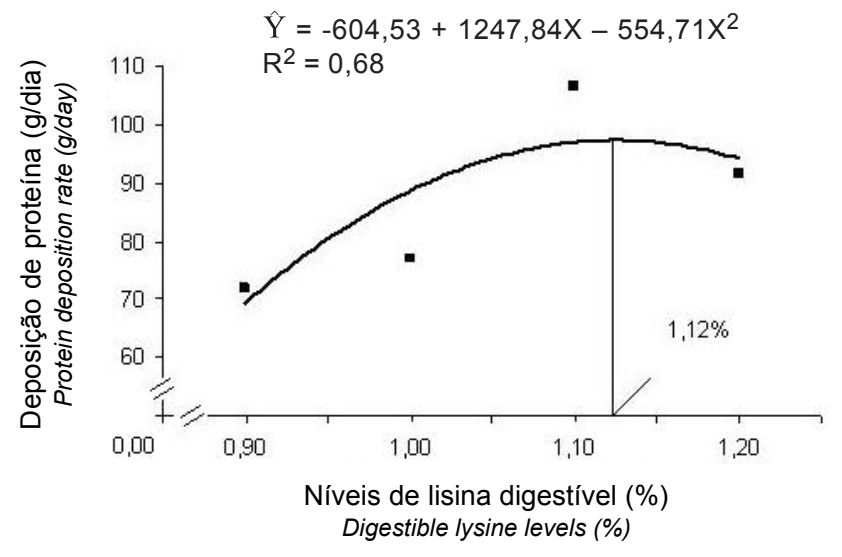

Figura 4 - Efeito dos níveis de lisina digestível da ração sobre a deposição diária de proteína em suínos machos castrados de 15 a $30 \mathrm{~kg}$.

Figure 4 - Effect of dietary digestible lysine levels on daily protein deposition of barrows from 15 to $30 \mathrm{~kg}$.

conteúdo de gordura na carcaça, o que foi verificado de forma numérica para porcentagem de gordura na carcaça e DG até o nível de $1,10 \%$ de lisina digestível.

O consumo de 12,03 g de lisina digestível/dia pelos animais, para os melhores resultados de conversão alimentar e deposição de proteína, permitiu deposição de proteína estimada de 97,22 g/dia, próximo aos $100 \mathrm{~g}$ de proteína, que, segundo o NRC (1998), podem ser depositados quando ocorre igual consumo diário de lisina digestível.

$\mathrm{O}$ valor de lisina digestível estimado para máxima DP neste trabalho $(1,12 \%)$ foi semelhante ao obtido por Fontes et al. (2005), que recomendaram, para leitoas de alto potencial genético de 15 a $30 \mathrm{~kg}$, nível de 1,13\% de lisina digestível. Mesmos valores de lisina para machos castrados e fêmeas mestiças de 15 a $30 \mathrm{~kg}$ foram encontrados por Souza (1997). Este fato corrobora a informação de Pupa et al. (2002) de que os efeitos do sexo sobre as exigências nutricionais dos suínos são evidentes somente a partir dos $30 \mathrm{~kg}$ de peso corporal.

Rostagno et al. (2005) preconizaram para suínos de 15 a

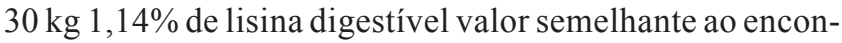
trado neste estudo. Entretanto, o nível de 1,12\% de lisina digestível é superior ao recomendado pelo NRC (1998) para animais na mesma fase de crescimento.

\section{Conclusões}

O nível de 1,12\% de lisina digestível, correspondente a um consumo de lisina digestível de 12,03 g/dia (3,42 g de lis digestível/Mcal de EM), proporcionou os melhores resultados de desempenho e características de carcaça em suínos machos castrados com alto potencial genético, de 15 a $30 \mathrm{~kg}$.

\section{Agradecimento}

À AGROCERES NUTRIÇÃO ANIMAL, pela cessão dos animais e das rações experimentais.

\section{Literatura Citada}

CAMERON, N.D.; McCUllough, E.; TROUP, K. et al. Serum urea concentration as a predictor of dietary lysine requirement in selected lines of pigs. Journal of Animal Science, v.81, p.91-100, 2003.

CHUNG, T.K.; BAKER, D.H. Ideal amino acid pattern for 10 kilograms pigs. Journal of Animal Science, v.70, p.31023111, 1992.

COLINA, J.J.; MILlER, P.S.; LEWIS, A.J. et al. Influence of crystalline or protein-bound lysine on lisien utilization for growth in pigs. Nebraska Swine Report, p.42-47, 2003.

DONZELE, J.L.; COSTA, P.M.A.; ROSTAGNO, H.S. et al. Efeitos de níveis de energia digestíveis na composição da carcaça de suínos de cinco a quinze quilos. Revista Brasileira de Zootecnia, v.21, p.100-1106, 1992.

DE LANGE, C.F.M.; BIRKETT, S.H.; MOREL, P.C.H. Protein, fat, and bone tissue growth in swine. In: LEWIS, A.J; SOUTHERN, L.L. (Eds.) Swine nutrition. Florida: CRC Press LLC, 2001. p.65-81.

D'MELLO, J.P.F. Amino acid supplementation of cereal-based diets for non-ruminants. Animal Feed Science and Technology, v. 45, p. $1-18,1993$.

EDMONDS, M.S.; BAKER, D.H. Amino acid excesses for young pigs: effects of methionine, tryptophan, threonine or leucine. Journal of Animal Science, v.64, p.1664-1671, 1987.

ELLIS, M. Efeitos do melhoramento genético, sexo, regime alimentar e peso de abate sobre o rendimento de carne magra na carcaça. In: SIMPÓSIO SOBRE RENDIMENTO E QUALIDADE DA CARne MAGRA SUÍNA, 1., 1998, Concórdia. Anais.. Concórdia: EMBRAPA-CNPSA, 1998. p.52-79.

FONTES, D.O.; DONZELE, J.L.; OLIVEIRA, R.F.M. et al. Níveis de lisina para leitoas selecionadas geneticamente para deposição de carne magra na carcaça, dos 15 aos $30 \mathrm{~kg}$. Revista Brasileira de Zootecnia, v.34, p.90-97, 2005.

FRIESEN, K.G.; NELSSEN, J.L.; GOODBAND, R.D. et al. Amino acid requirements for high-lean growth gilts. In: ANNUAL MEETING OF THE AMERICAN ASSOCIATION OF SWINE PRACTITIONERS, 25., 1994, Chicago. Proceedings... Chicago: ASSP, 1994. p.312-320.

HENRY, Y. Dietary factors involved in feed intake regulation in growing pigs: a review. Livestock Production Science, v.12, p.339-354, 1985.

JAMES, B.W.; TOKACH, M.D.; GOODBAND, R.D. et al. The optimal true ileal digestible lysine requirement for nursery pigs between 27 to $44 \mathrm{lb}$. Swine Day, p.63-65, 2002.

KENDALL, D.C.; ALLEE, G.L.; GOURLEY, G. et al. Effects of lysine source on growth performance of 11 to $25 \mathrm{~kg}$ pigs. Journal of Animal Science, v.81, p.139, 2003 (suppl.1)

KESSLER, A.M. Exigências nutricionais para máximo rendimento de carne em suínos. In: SIMPÓSIO SOBRE RENDIMENTO E QUALIDADE DA CARNE SUÍNA, 1998, Concórdia. Anais... Concórdia: EMBRAPA-CNPSA, 1998. p.18-25.

MAXWELL, C.V. Potential for reducing nitrogen excretion in swine. Animal Research Report, p.186-196, 1996.

MERINO, C.B.; GUERRERO, A.F.; CUARÓN, I.J.A. Requerimientos de lisina digestible en lechones de 14 a 35 y cerdos de 35 a $55 \mathrm{~kg}$. In: CONGRESSO NACIONAL DE LA AMENA, 11., CONGRESSO LATINOAMERICANO DE NUTRICIÓN ANIMAL, 1., 2003, Cancún. Memorias... Cancún: AMENA, 2003. p.349-350. 
MORETTO, V.; DONZELE, J.L.; OLIVEIRA, R.F.M. et al. Níveis de lisina para suínos da raça Landrace, de 15 a $30 \mathrm{~kg}$. Revista Brasileira de Zootecnia, v.29, p.803-809, 2000.

NATIONAL RESEARCH COUNCIL - NRC. Nutrient requirements of swine. 10.ed. Washington, D.C.: National Academic Press, 1998. $189 \mathrm{p}$

PUPA, J.M.R.; TEIXEIRA, A.O.; NOGUEIRA, E.T. et al. Atualização sobre nutrição de suínos em crescimento e terminação. In: CONGRESSO LATINO AMERICANO DE SUINOCUltURA, 1., 2002, Foz do Iguaçu. Anais... Foz do Iguaçu: EMBRAPA-CNPSA, 2002. p.145-164.

ROSTAGNO, H.S.; ALBINO, L.F.T.; DONZELE, J.L. et al. Composição de alimentos e exigências nutricionais de aves e suínos: tabelas brasileiras. Viçosa, MG: Universidade Federal de Viçosa, 2000. 141p.

ROSTAGnO, H.S.; ALBINO, L.F.T.; DONZELE, J.L. et al. Tabelas brasileiras para aves e suínos: composição de alimentos e exigências nutricionais. Viçosa, MG: Universidade Federal de Viçosa, 2005. 186p.

ROTH, F.X.; EDER, K.; KIRCHGESSNER, M. The effect of energy density and the lysine to energy ratio of diets on the performance of piglets. Journal of Animal Physiology Animal Nutrition, v.82, p.1-7, 1999.

SCHINCKEL, A.P.; De LANGE, C.F.M. Characterization of growth parameters needed as inputs for pig growth models. Journal of Animal Science, v.74, n.8, p.2021-2036, 1996.

SILVA, D.J. Análise de alimentos: métodos químicos e biológicos. Viçosa, MG: Universidade Federal de Viçosa, 1990. 166p.
SMITH, J.W.; TOKACH, M.D.; O'QUINN, P.R. et al. Effects of dietary energy density and lysine:calorie ratio on growth performance and carcass characteristics of growing-finishing pigs. Journal of Animal Science, v.77, p.3000-3006, 1999.

SOUZA, A.M. Exigências nutricionais de lisina para suínos mestiços, de 15 a $95 \mathrm{~kg}$ de peso. Viçosa, MG: Universidade Federal de Viçosa, 1997. 81p. Dissertação (Mestrado em Zootecnia) - Universidade Federal de Viçosa, 1997.

STAHLY, T.S.; WILLIAMS, N.H.; SWENSON, N.H. Impact of genotype and dietary regimen on growth of pigs from 6 to $25 \mathrm{~kg}$. Journal of Animal Science, v.72, p.165, 1994 (suppl. 1).

TRINDADE NETO, M.A.; PETELINCAR. I.M.; BERTO, D.A. et al. Níveis de lisina para leitões na fase incial-I do crescimento pósdesmame: composição corporal aos 11,9 e 19,0 kg. Revista Brasileira de Zootecnia, v.33, n.6, p.1777-1789, 2004 (supl. 1).

UNIVERSIDADE FEDERAL DE VIÇOSA - UFV. Sistemas de Análises Estatísticas e Genéticas - SAEG. Viçosa, MG: 1997 (Versão 8.0).

URYNEK, W.; BURACNEWSKA, L. Effect of dietary energy concentration and apparent ileal digestible lysine:metabolizable energy ratio on nitrogen balance and growth performance of young pigs. Journal of Animal Science, v.81, n.5, p.1227$1236,2003$. 